\title{
Reconceptualising manual handling: Foundations for practice change
}

\author{
Kate Kay, Nel Glass, Alicia Evans \\ Australian Catholic University, Australia. \\ Correspondence: Professor Nel Glass. Address: 115 Victoria Parade, Fitzroy, VIC 3065, Australia Locked Bag 4115, \\ Fitzroy, MDC, VIC 3065, Australia. Telephone: 61-414-822-602. Email: Nel.Glass@acu.edu.au \\ Received: March 4, 2012 \\ Accepted: March 27, $2012 \quad$ Published: August 1, 2012 \\ DOI : 10.5430/jnep.v2n3p203 \\ URL: http://dx.doi.org/10.5430/jnep.v2n3p203
}

\section{Abstract}

Background: Healthcare involves complex manual handling tasks that are unique to the industry. Despite research intended to improve carer safety, substantial rates of manual handling injuries persist within the nursing profession. This paper reviews manual handling issues arising from patient care activities and the strategies deployed in healthcare facilities to reduce musculoskeletal injuries.

Discussion: Conventional programs aimed at reducing nurses' work-related manual handling injuries include assumptions regarding evidence, transferability to the clinical setting and efficacy. Additionally, intervention success is commonly measured by administrative data comprising incident reports and injury rates. However official statistics are contrasted with self-reported injury rates in several studies. The complex nature of the injury mechanism and the obscured visibility of musculoskeletal disorders hinder detection of manual handling injuries and attribution of causality. In turn, this hampers the development of successful injury prevention strategies. Training programs reliant on specific techniques and assistive devices have had limited success. This paper questions the appropriateness of training and compliance strategies to manage manual handling risks in nursing practice and expounds a re-examination of the premises upon which manual handling programs are based.

Conclusion: It is argued that the current conceptualisation of manual handling has limited the development of effective injury prevention programs for healthcare. It emphasises the enforcement of guidelines rather than a critique of other influences on practice. Approaching manual handling from a different perspective, inclusive of nurses' knowledge, is a way forward into the complex environment of manual handling in healthcare contexts. Voicing and validation of nurses' manual handling knowledge offers critical knowledge necessary to improve manual handling safety for nurses by foregrounding contextual influences that have previously been undervalued.

\section{Key words}

Evidence-based practice, Injury prevention, Manual handling, Manual handling training, Musculoskeletal disorders, Nurses, Voice 


\section{Introduction}

Healthcare involves complex manual handling tasks that are unique to the industry and despite research intended to improve carer safety, substantial injury rates arising from manual handling activities persist within the nursing profession. Manual handling involves the application of force to move an object or person and is inherent in many of the tasks performed during the delivery of nursing care to patients ${ }^{[1-4]}$. In Australia, manual handling is viewed as the performance of physical actions utilising the musculoskeletal system ${ }^{[1]}$. Definitions for manual handling vary across the international literature, although a universal theme of musculoskeletal exertion is apparent and broadly consistent with the Australian definition ${ }^{[3,5]}$.

This paper reviews manual handling issues arising from patient care activities and the strategies deployed in healthcare facilities to reduce musculoskeletal injuries. It was developed subsequent to a presentation delivered at the inaugural 'Professional Issues in Practice Conference: Our Professions in Focus', an event hosted by the Australian Nursing Federation in Melbourne, Australia in June, 2011. The conference comprised generalist professional topics over a two-day period, with a dedicated manual handling stream on the second day of proceedings. Despite this demarcation with respect to scope, the authors' paper was scheduled on the first day of the conference. The benefit of this unexpected programming decision was the opportunity to access nurses whose interests comprised a broad range of topics rather than a sole focus on manual handling issues. The encouraging responses of the delegates and their enthusiastic engagement with the presentation illustrated an emerging need to challenge the taken-for-granted views on manual handling, and most critically, intent to improve the working lives of nurses.

\section{Aims}

Two decades ago Street ${ }^{[6]}$ espoused the need to collaboratively critique knowledge claims that inform nursing practice. The potentially transformative intent of her work was made explicit by examining whose interests were best served by privileging knowledge claims, the embedded power relations and uncovering the dominant ideology informing nursing actions. This theoretical position, informed by critical social science argues for the liberation of oppressed groups by collective group action ${ }^{[7,8]}$.

Socio-political critiques of nursing practice utilizing emancipatory paradigms are not new. Conversely they have proliferated throughout the nursing literature, and scholars have continued to report on the oppression of nurses and oppressive working conditions ${ }^{[9-14]}$. However, such critiques do offer a different theoretical lens to examine traditional areas of practice such as manual handling. Encouraging nurses to actively reflect on the socio-political constraints within which they practice could similarly facilitate their emancipation from oppressive structures relating to their manual handling safety.

Street ${ }^{[6]}$ posited that an increased awareness of socially constructed values and taken-for-granted meanings promotes opportunities for change. Arguably, a critical analysis of the manual handling context for nurses could equally be the basis for transformation relating to occupational safety. In addition, promoting dialogue amongst nurses outside the confines of their employer organisations enables nurses to share and reflect upon their manual handling experiences. This assists in addressing the nurses' visibility dialectic consequent to their marginalised position in healthcare ${ }^{[6]}$. The dialectical tension that arises from the public nature of the nursing workplace places nurses under pressure and undermines their professional confidence, due to the constant scrutiny of their practice ${ }^{[6]}$. The subordination of nursing knowledge to medico-scientific, technical knowledge compounds the nurses' experiences of marginalisation as nurses learn to act as though they were invisible in response to these oppressive conditions ${ }^{[6]}$.

Consideration of, and discussion relating to the above factors was congruent with a conference paper at a professional nursing conference. The aim of the present paper is to discuss the key concepts and further progress the identified need to critically analyse dominant values and norms that impact upon manual handling issues for the nursing profession. The active expression of nurses' manual handling concerns and experiences contributes to validation of nurses' knowledge, promotes reflexivity and the generation of new meaning. This process of increased awareness resulting from the identification of hegemonic structures has the potential for the transformation of nurses' manual handling circumstances. 


\section{Background}

\subsection{The relationship between manual handling and nursing activities}

Manual handling encompasses activities that require the application of force to move an object or person ${ }^{[1-3]}$. During the provision of patient care, numerous manual handling actions undertaken have the potential to cause injuries to the nursing staff ${ }^{[4]}$. Conventionally, manual handling injuries have been viewed as sudden-onset in nature arising from a specific event. However a contrasting, gradual-onset injury mechanism has become increasingly apparent over recent years. Both categories of manual handling injuries are referred to as musculoskeletal disorders (MSDs) and include a broad range of symptoms across a variety of body parts ${ }^{[1,15]}$. Notably, the repeated exposure of nurses to the substantive physical and psychosocial demands of their occupation continues to be associated with a high prevalence of musculoskeletal disorders within their profession ${ }^{[2,16-24]}$.

Recent research has identified the presence of psychosocial risk factors for work-related manual handling injuries ${ }^{\text {[24, 25] }}$. The mechanisms postulated to explain their direct contribution to the development of MSDs are based on physiological changes, such as increased muscle tension, endocrine, hormonal and immune system responses, in addition to observable behaviour changes resulting from attempts to cope with workplace demands ${ }^{[1,3,24-26]}$. Examples of psychosocial risks for MSDs include high workloads or effort required with little perceived reward, tight deadlines and a lack of control over the work and working methods, including shift patterns or work rates determined by machines or systems. These examples are particularly pertinent to nurses for whom 'work intensification' is a substantial part of their professional practice.

\subsection{Historical perspectives on manual handling and nursing}

Historical changes in the structure of the work of nursing demonstrates the increased manual handling demands experienced by nurses over the past century ${ }^{[27]}$. Figure 1 illustrates the evolving nature of the nursing role and the changing context for the delivery of patient care.

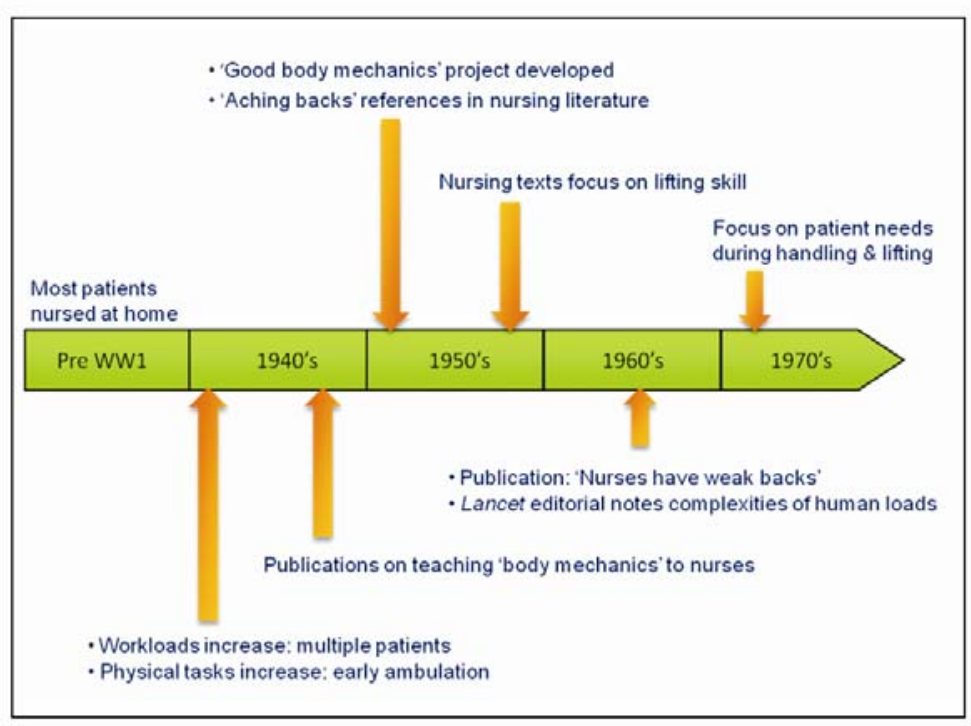

Figure 1. Historical background: Nursing role and manual handling

Early in the twentieth century, patients were nursed individually in the home environment. Progression in healthcare, as shown in Figure 1, included the adaptation of the nursing role to suit hospital environments in conjunction with increased physical demands arising from expanded patient responsibilities ${ }^{[27]}$. By mid-century, the physical ability and competency of nurses was questioned in response to emerging back injuries, however the lack of theoretical merit for patient handling advice remained unchallenged. Throughout this period, medical or allied health professionals had oversight of nurses' 
patient handling techniques ${ }^{[27]}$. Additionally, the primacy of patient needs remained paramount as pertinently illustrated by a High Court decision in the United Kingdom ${ }^{[2]}$. This case exemplified the legal divergence regarding patient and carer wellbeing, deeming safe handling policies potentially unlawful. The judgment stipulated that manual exertion, rather than assistive technology, may be required when conflicts exist between carer and patient considerations ${ }^{[2]}$.

\subsection{Overview of manual handling injury prevention in healthcare}

Although training and education are low order risk-control strategies, these strategies have been widely adopted within the healthcare industry ${ }^{[28]}$. Manual handling training typically relies on traditional knowledge and a focus on the strength, technique and compliance of individuals ${ }^{[29,30]}$. Contemporary policy guidelines have emphasised the training of staff in specific lifting or transfer techniques in order to the combat the risks of occupational injury. Hence this approach to injury prevention aspires to modify the actions of nurses in order to meet the task demands of their occupation, rather than a restructuring of the work environment to reduce the risk of injury ${ }^{[31-33]}$.

More recently, an ergonomic approach to manual handling has emerged and stimulated the development of assistive devices for manual handling tasks. Instruction in the use of specialised handling equipment has been included within training programs and may reinforce an education-based approach to manual handling risks at the expense of alternative responses ${ }^{[19,34-40]}$. However, the persistence of high injury rates amongst nurses demands interrogation of contemporary injury prevention strategies, particularly those reliant on training as the key component ${ }^{[27,41,42]}$. Of significance, systematic literature reviews have repeatedly demonstrated the inadequacy of training staff in optimal work techniques as a preventative measure for manual handling injuries and consistently identified the need for more comprehensive strategies to resolve manual handling issues in healthcare ${ }^{[43-49]}$. However training-based programs for injury prevention continue to be a common intervention choice within the healthcare industry.

\section{Method}

The historical overview of nursing presented above highlights the key points related to the development of manual handling interventions intended to prevent work-related MSDs. Traditionally, approaches to nurses' manual handling issues have been dominated by overriding concerns for patient welfare and medical ideology that lacks a clear, consistent evidence-base ${ }^{[27]}$. The development of injuries irrespective of lifting advice has directed attention to deficits in the abilities, strength or compliance behaviour of individual nurses.

Based on assumptions of the adequacy of manual handling injury prevention programs to effectively reduce injuries, enforcement of recommended strategies has dominated the injury reduction objectives of healthcare organisations. Shortfalls in achieving reductions in manual handling injury statistics directs attention to agency rather than program structure, as the latter is perceived to be soundly based on scientific evidence. In this manner, variations in individual performance during discrete manual handling activities are thought to explain continued high injury rates, and competency assessments become the cornerstone of manual handling programs.

If a consensus is achieved regarding this normative view for conceptualisation of manual handling injuries, the socio-political organisation of healthcare is shielded from rigorous critique in that investigation of deficits is directed towards individual performance rather than the system in which manual handling is undertaken. The legacy of conceiving manual handling in this way has carried over into contemporary approaches to manual handling as illustrated by various assumptions embedded within manual handling programs. Many of the underlying premises of intervention programs are not made explicit and these assumptions will be discussed following an exploration of manual handling definitions and related concepts.

\section{Defining concepts related to manual handling}

International definitions pertaining to manual handling vary and the lack of a universal and comprehensive definition can complicate the identification of both manual handling activities and their consequences. Ambiguous terminology has the potential to generate confusion, constrain thinking and exclude key components from consideration. International literature references the phrases 'manual handling' or 'moving and handling' and is noted to be less concise in American 
guidelines ${ }^{[1,2,50]}$. In Australia, manual handling is defined by the performance of physical actions utilising the musculoskeletal system ${ }^{[10]}$. Similar explanations for manual handling exist internationally with the introduction of a manual handling directive in the European Union in 1990 forming the basis for the updating of regulations in the United Kingdom in $1992^{[3,5]}$.

Definitions for manual handling become particularly problematic if injuries are then defined only in terms of physical parameters. Injuries bounded by physical characteristics alone imply causation that excludes important psychosocial hazards and contextual influences ${ }^{[51]}$. The latter factors contribute substantially to the generation of injuries yet are easily overlooked when investigation is confined to physical actions and task performance by the injured nurse is under suspicion $^{[24,26,52,53]}$.

An example of the conceptual restrictions that arise from socially-constructed terminology and meaning is the development and reference to "No Lift" policies and various other trademarked titles of injury prevention programs. Whilst manual handling risks are not confined to lifting or heavy exertion alone, the linguistic labels attached to intervention programs can inadvertently propagate misconceptions regarding the nature of manual handling, and strategies to combat injury risks. The continued use of misleading terminology can easily direct attention away from other hazardous physical activities such as pushing, pulling and prolonged static postures ${ }^{[1,3]}$. This perspective simultaneously reinforces a narrow, focus on specific tasks, failing to embrace associated contextual features for manual handling issues.

\section{Discussion}

\subsection{Embedded assumptions within manual handling programs}

It is generally believed that the current manual handling programs are evidence-based, assuming that the evidence for strategic interventions has been scientifically obtained and validated. The fallacy of this belief has already been noted within this paper in reference to the outcomes of systematic literature reviews that challenge the efficacy of training as a solution to manual handling issues ${ }^{[43-49]}$. Furthermore, recommended guidelines can portray an image of evidence as static and acontextual, implying that a single 'best practice' is obtainable, desirable and fixed ${ }^{[54,55]}$. Illustrative of the changes in evidence regarding manual handling is the summary presented by the Australian Safety and Compensation Council's (ASCC) literature review ${ }^{[24]}$. The current regulations and guidelines for manual handling practice in Australia are informed by evidence obtained in the 1980s and early 1990s that primarily encompasses the consideration of physical risks for manual handling activities. Whilst environmental constraints within the workplace and psychosocial influences have become apparent in recent years, an ongoing focus on the physical nature of task demands has persisted. Currently guidelines for the reduction of manual injuries are dominated by advice regarding physical hazards, and the uptake of systemic solutions remains slow ${ }^{[1,3,24]}$.

The complex nature of manual handling issues was highlighted in the critical review by Denis et al ${ }^{[45]}$ who noted the importance of context in relation to manual handling initiatives. Denis et al recommended the inclusion of contextual considerations within the design and assessment of manual handling programs, and attempted to incorporate contextual factors into their classification of ergonomic intervention types. However, they were unable to make substantive comparisons or recommendations regarding the implementation processes noting an "almost total lack of information on the intervention process" [emphasis added] ${ }^{[45]}$ within standard literature appraisals. Hence they concluded that the ergonomic approach had become the dominant model for MSD intervention by informal consensus amongst occupational health professionals, rather than the result of systematic examination of evidence for this position. Thus the key components for successful implementation of interventions have been overlooked as implementation processes have not been reported sufficiently to enable comprehensive analysis and review ${ }^{[45]}$.

If the identification of strategies to combat manual handling risks have been presumed adequate, then further issues arise when intervention programs are also assumed suitable for clinical settings in relation to both program content and implementation ${ }^{[56]}$. Injury prevention programs deployed in healthcare facilities make two key assumptions regarding implementation: firstly, that skills transfer has been successfully achieved within the teaching environment and secondly, 
that the recommended practices and skills can be applied in clinical environments. The high MSD rates reported internationally and the lack of scrutiny of training content, delivery and suitability for clinical use results in a pressing need to question the legitimacy of such assumptions ${ }^{[57,58]}$.

Referring back to the Australian Professional Issues Conference introduced above, the tension for nurses has now reached critical levels in terms of manual handling injuries, prevention programs and practical challenges in the clinical setting. This was exemplified by the responses of delegates attending the aforementioned conference presentation. A brief segment scheduled to allow nurses to share ideas in small groups was actively embraced by clinicians wishing to explore the notion of nurses voicing their perspectives on manual handling, and the potential for validation and empowerment by this means. The enthusiastic engagement of almost four hundred participants was highly audible within the first minute of this exercise. Upon return to one large assembly, nurses were eager to publicly express their thoughts and concerns before the entire group and time-scheduling considerations limited the number who ultimately had the opportunity to do so in this setting. A passionate nurse initially welcomed the discussion stating "I just want to come up and hug you! I am so relieved to hear someone say this at last!” Several speakers offered further comments, including their injury and reporting fears, frustration in attempts to safely perform manual handling tasks without essential resources and specific examples of budgetary constraints precluding safe handling. A dialectical tension was exemplified by nurses who spoke of their confusion surrounding practice guidelines unsuitable for clinical settings and the blame they attributed to themselves or colleagues for deviance from these guidelines. Notably, there appeared to be widespread familiarity amongst the conference attendees with the issues presented by their colleagues. Individual approaches to the presenter by audience members throughout the conference subsequently confirmed this observation.

In summary, whilst individual non-compliance with recommended guidelines appears a plausible explanation for the high prevalence of injuries amongst nurses, the authors argue that this response ignores other healthcare complexities relating to manual handling, including program and implementation deficits and most importantly, the role of actual healthcare contexts ${ }^{[59]}$. It is suggested that exploring alternative explanations for the persistence of manual handling injuries is crucial to the advancement of nurses' safety during the provision of patient care.

\subsection{Assumptions related to injury rates}

A common measure of manual handling injury prevalence is the number of claims for compensation received ${ }^{[36,37,40,60]}$. In Australia, the National Data Set (NDS) represents Workers' Compensation statistics collated across all states and territories and this data is utilised by administrators to assess the efficacy of intervention programs. However, compensation claim approvals are only a subset of manual handling injuries as claim numbers are consequential to both reporting and approval processes ${ }^{[61]}$. Thresholds for serious injury claims are defined in Australia as permanent or temporary incapacity necessitating time off work for a minimum of one week ${ }^{[24]}$. Hence formal reporting rates and compensation claim statistics do not recognise all manual handling injuries and thus underestimate injury prevalence $^{[18,56,58]}$.

The ASCC noted several difficulties related to claims reporting data, including potential deficits in the manual handling knowledge of those providing the data, thereby reducing data accuracy and confidence in conclusions based on these measures ${ }^{[24]}$. Furthermore, injury reporting and compensation documents commonly assume sudden-onset injury mechanisms (located at a particular point in time) and overlook the cumulative, gradual-onset mechanism of injury ${ }^{[24]}$. The inability to register injuries that are not easily linked to a particular event generates inaccurate perceptions of true injury rates and thereby reduces the visibility of nurses' manual handling injuries. Additionally, the physical focus contained within the coding and classification system for manual handling injuries within Australia conceals the contribution of psychosocial factors.

Underreporting of injuries and incidents is believed to be much higher in healthcare in comparison with other industries, although the extent of this problem remains difficult to quantify ${ }^{[17,24]}$. Safe Work Australia, the statutory agency established in 2009 to oversee work-related compensation in Australia, conducted an investigation into factors influencing workers' injury reporting rates and acknowledged that the NDS inherently underestimates the true number of injuries due to these reporting issues ${ }^{[62]}$. Their findings mirror that of earlier Australian research that identified underreporting of manual handling injuries in healthcare ${ }^{[18]}$. Rationale for conscious decisions by nurses to refrain from reporting injuries 
included perceptions that injuries were not sufficiently serious to warrant documentation, despite seeking medical care or taking time off work in some instances. Other rationale included fear of dismissal, fear of being stigmatised, inconvenience or excessive efforts required to report injuries and unexpected variations in recovery rates ${ }^{[18,62]}$.

\subsection{A critical perspective for manual handling in healthcare}

The language or discourse relating to a specific area of knowledge is framed by a particular worldview that actively shapes associated conceptual frameworks ${ }^{[63]}$. This discursive organisation of knowledge and practices may lead to aspects that are hidden or misunderstood consequent to taken-for-granted ways embedded in the dominant ideology. Folkman and Rankin ${ }^{[64]}$ presented a critical analysis that succinctly overviews the discursive frameworks of biomedical science, law, management and safety and their impact upon nurses’ medication practices. The privileged biomedical science approach precludes a comprehensive understanding of medication administration by neglect of the complex social organisation inherent within healthcare. Legal and regulatory discourses produce an emphasis on the legal responsibility of nurses, and create a proliferation of rules to manage risk. Whilst an emphasis on policies and procedures may appear to protect nurses, the organisational interests are well served by the strengthening of systems that demand nurses' accountability and efficiency. Compliance with this ideology due to fear of liability and litigation thereby sustains regulation of nursing practice and maintains the status quo. The discourse of management further reinforces the legal framework, again congruent with organisational interests relating to efficiency and cost-effectiveness. Finally, the aggregate nature of the monitoring of adverse events, a consequence of the discourse of safety, provides trend data but cannot capture varied local knowledge practices and complexities and further constrains nursing practice ${ }^{[64]}$.

In principle, the same concepts discussed above could also constrain the manual handling practices of nurses. The discursive frameworks contribute to the dialectical tension reported by nurses regarding conflicts between the organisational goals of productivity and the occupational wellbeing of nurses. In recognition of the boundaries of conventional injury prevention approaches and the failure of such programs to consistently achieve their stated objectives, the authors of this paper propose that it is imperative to undertake a critical analysis of the organisation of manual handling in healthcare.

The way in which we perceive manual handling is influenced by conceptual definitions that in turn limit our thinking and exploration of the construct of manual handling. Consequently, key aspects of manual handling can be overlooked, preventing the identification of alternatives to the current organisation of manual handling practice in healthcare. Factors that do not feature in the contemporary conceptualisation of manual handling are ignored, devalued or rejected and the socio-political status quo is maintained at the expense of the nurses' welfare whilst injuries continue unabated. The privileged position of the scientific and medical perspectives that govern the social organisation of healthcare and safety, and the way management objectives are implemented all exert influence over the manual handling responses currently available to nurses in their professional roles. The limitations imposed by these discourses constrain the options for improving manual handling safety for nurses and therefore it is critical to foreground the impact of these socio-political structures.

Whilst a dominant ideology that conceives nurses as non-compliant currently drives efforts for manual handling injury reduction towards enforcement strategies, this approach has been broadly ineffective as demonstrated by multiple systematic literature reviews. Increasing the visibility of nurses' manual handling issues and injuries, inclusive of giving voice to nurses, facilitates the discovery of potentially transformative alternatives to contemporary manual handling interventions. Crucial to this objective is the validation of nurses' manual handling experiences and knowledge, in conjunction with considerations regarding the reorganisation of the socio-political structures that constrain nurses.

\section{Conclusion}

Sustainable solutions for manual handling issues in the healthcare context have proved elusive with key elements for successful programs yet to be identified. One way to advance manual handling knowledge for clinical environments is to consult with those clinicians who are intimately acquainted with the conditions under which manual handling is performed and incorporate this specialised knowledge into the conceptualisation of manual handling. Nurses are ideally placed to 
offer unique insights into the contextual factors that influence patient handling and therefore they can make critical contributions to knowledge generation in this field. As nurses function within a variety of historical, social, political, cultural and economic contexts, emancipatory reflection affords an opportunity to critically analyse these contextual features and their impact upon nursing practice. This is particularly important as manual handling has traditionally been driven by medical and allied health professionals with little consideration given to nurses' knowledge ${ }^{[27]}$.

The explicit intention of critical research is to generate knowledge that has the potential for emancipation ${ }^{[65,66]}$. Gaining an understanding of manual handling from the nurses' perspectives provides an opportunity to restructure the concept of manual handling and interrogate the conventional approaches to the management of manual handling risks. An enhanced awareness of the critical issues pertaining to patient handling, resulting from the inclusion of nurses into the manual handling discourse, provides an opportunity to review and reconstruct the elements required for successful manual handling interventions and transform nurses’ manual handling practice.

\section{Relevance to clinical practice}

The nature of patient care presents manual handling challenges that have not been adequately addressed to date. Manual handling is an inherent part of nursing practice and continues to generate significant injury rates within the profession. Maintaining a silence regarding the difficulties that nurses face perpetuates the oppression of nurses, as is consistently documented ${ }^{[9,67,68]}$. Conversely, encouraging nurses to 'speak the unspeakable' can foreground dialogue that has previously been overlooked, devalued or oppressed ${ }^{[13,66,69]}$. In effect, the voicing of nurses' knowledge can be an opportunity to challenge the expectation of nurses to "accept the unacceptable".

Dialogue inclusive of nurses' knowledge of manual handling issues can offer a better understanding of the specific issues related to clinical settings and prompt reconsideration of manual handling and the way in which it is conceptualised. This has the potential to generate injury prevention strategies more suitably tailored to the characteristics of healthcare contexts and to improve the occupational wellbeing of nurses.

\section{Conflict of interest statement}

No conflict of interest.

\section{References}

[1] ASCC. National Code of Practice for Prevention of Musculoskeletal Disorders caused from Performing Manual Tasks. Canberra: Australian Safety and Compensation Council, 2007.

[2] Hignett S, Fray M, Rossi MA, Tamminen-Peter L, Hermann S, Lomi C, et al. Implementation of the Manual Handling Directive in the healthcare industry in the European Union for patient handling tasks. International Journal of Industrial Ergonomics. 2007; 37: 415-423.

[3] HSE. Manual Handling of Loads - Guideline to the Manual Handling Operations Regulations. London: Health \& Safety Executive, 1992.

[4] Holman G. Decision factors in patient handling. In Proceedings of the Fourth Annual Regional National Occupational Research Agenda (NORA) Young/New Investigators' Symposium: 20-21 April 2006; Salt Lake City, Utah. Edited by DS Bloswick, KT Hegmann, and RF Sesek. 2006

[5] European Agency for Safety and Health at Work. Directive on the minimum health and safety requirements for the manual handling of loads where there is a risk particulary of back injury to workers. Florence, Italy: European Agency for Safety and Health at Work, 1990.

[6] Street A. Inside nursing: a critical ethnography of clinical nursing. New York: State University of New York, 1992.

[7] Fay B. Critical social science: liberation and its limits. New York: Cornell University Press, 1987.

[8] Fay B. Contemporary philosophy of social science. Oxford: Blackwell Publishers Ltd, 1996.

[9] Dong D, Temple B. Oppression: a concept analysis and implications for nurses and nursing. Nursing Forum. 2011; 46: 169-176. http://dx.doi.org/10.1111/j.1744-6198.2011.00228.x

[10] Fletcher K. Beyond dualism: leading out of oppression. Nursing Forum. 2006; 41: 50-59. http://dx.doi.org/10.1111/j.1744-6198.2006.00039.x

[11] Roberts S. Oppressed group behavior: implications for nursing. Advances in Nursing Science. 1983; 5: 21-30. 
[12] Roberts SJ. Oppressed group behavior and nursing. In A history of nursing ideas. LC Andrist, KN Patrice, and KA Wolf, ed. Sudbury, Massachusetts: Jones and Bartlett. 2006; 23-33.

[13] Rose J, Glass N. An Australian investigation of emotional work, emotional wellbeing and professional practice: An emancipatory inquiry. Journal of Clinical Nursing. 2010; 19: 1405-1414.

[14] Glass N, Davis K. Reconceptualizing vulnerability: Deconstruction and reconstruction as a postmodern feminist analytical research method. Advances in Nursing Science. 2004; 27: 82.

[15] WorkSafe Victoria. Code of Practice for Manual Handling. Melbourne: Victorian Workcover Authority, 2000.

[16] Owen BD, Keene K, Olson S. An ergonomic approach to reducing back/shoulder stress in hospital nursing personnel: a five year follow up. International Journal of Nursing Studies. 2002; 39: 295-302.

[17] ASCC. Occupational Exposure in Australian Nurses. Canberra: Australian Safety and Compensation Council, 2008.

[18] Retsas A, Pinikahana J. Manual handling activities and injuries among nurses: an Australian hospital study. Journal of Advanced Nursing. 2000; 31: 875-883.

[19] Stenger K, Montgomery LA, Briesemeister E. Creating a culture of change through implementation of a safe patient handling program. Critical Care Nursing Clinics of North America. 2007; 19: 213-222.

[20] Nelson A, Matz M, Chen F, Siddharthan K, Lloyd J, Fragala G. Development and evaluation of a multifaceted ergonomics program to prevent injuries associated with patient handling tasks. International Journal of Nursing Studies. 2006; 43: 717-733.

[21] Smedley J, Inskip H, Trevelyan F, Buckle P, Cooper C, Coggon D. Risk factors for incident neck and shoulder pain in hospital nurses. Occupational and Environmental Medicine. 2003; 60: 864.

[22] Trinkoff AM, Lipscomb JA, Geiger-Brown J, Storr CL, Brady BA. Perceived physical demands and reported musculoskeletal problems in registered nurses. American Journal of Preventive Medicine. 2003; 24: 270-275.

[23] Safe Work Australia. Compendium of workers' compensation statistics Australia 2008-09. Canberra: Safe Work Australia, 2011.

[24] ASCC. Research on the prevention of work-related musculoskeletal disorders. Canberra, Australian Safety and Compensation Council. 2006.

[25] What are psychosocial risk factors? Available from: http://www.hse.gov.uk/msd/mac/psychosocial.htm (2 February 2012, date last accessed).

[26] European Agency for Safety and Health at Work. Expert forecast on emerging pyschosoical risks related to occupational safety and health. Luxembourg: Office for Official Publications of the European Communities, 2007.

[27] Collins J, Menzel N. Scope of the problem. In Safe patient handling and movement. A Nelson, ed. New York, NY: Springer. 2006; 3-26.

[28] Nelson A, Baptiste AS. Evidence-based practices for safe patient handling and movement. Orthopaedic Nursing. 2006; 25: 366-379.

[29] Hignett S, Crumpton E. Competency-based training for manual handling. Applied Ergonomics. 2007; 38: 7-17.

[30] Nelson A, Collins J, Siddharthan K, Matz M, Waters T. Link between safe patient handling and patient outcomes in long-term care. Rehabilitation Nursing. 2008; 33: 33-43.

[31] Allen R, Jackson S, Marsden H, McLellan DL, Gore S. Transferring people safely with manual handling equipment. Clinical Rehabilitation. 2002; 16: 329-337.

[32] Baptiste A, Boda S, Nelson A, Lloyd J, Lee W. Friction-reducing devices for lateral patient transfers: a clinical evaluation. AAOHN Journal. 2006; 54: 173-180.

[33] Ilmarinen J. Work ability - a comprehensive concept for occupational health research and prevention. Scandinavian Journal of Work, Environment and Health. 2009; 35: 1-5.

[34] Engkvist I-L. Evaluation of an intervention comprising a No Lifting Policy in Australian hospitals. Applied Ergonomics. 2006; 37: 141-148.

[35] Lim HJ, Black TR, Shah SM, Sarker S, Metcalfe J. Evaluating repeated patient handling injuries following the implementation of a multi-factor ergonomic intervention program among health care workers. Journal of Safety Research. 2011; 42: 185-191. http://dx.doi.org/10.1016/j.jsr.2011.05.002

[36] Bird P. Reducing manual handling workers compensation claims in a public health facility. Journal of Occupational Health \& Safety - Australia \& New Zealand. 2009; 25: 451-451-459.

[37] Martin PJ, Harvey JT, Culvenor JF, Payne WR. Effect of a nurse back injury prevention intervention on the rate of injury compensation claims. Journal of Safety Research. 2009; 40: 13-19.

[38] Knibbe H, Knibbe N, Klaassen A. Safe patient handling program in critical care using peer leaders: lessons learned in The Netherlands. Critical Care Nursing Clinics of North America. 2007; 19: 205-211.

[39] Badii M, Keen D, Yu S, Yassi A. Evaluation of a comprehensive integrated workplace-based program to reduce occupational musculoskeletal injury and its associated morbidity in a large hospital. Journal of Occupational \& Environmental Medicine. 2006; 48: 1159-1165. http://dx.doi.org/10.1097/01.jom.0000243416.18334.c8

[40] Collins J, Wolf L, Bell J, Evanoff B. An evaluation of "best practices" musculoskeletal injury prevention program in nursing homes. Injury Prevention. 2004; 10: 206-211. http://dx.doi.org/10.1136/ip.2004.005595

[41] Hignett S, Crumpton E, Ruszala S, Alexander P, Fray M, Fletcher B. Evidence-based patient handling: tasks, equipment and interventions. London: Routledge, 2003. 
[42] Nelson A, Fragala G, Menzel N. Myths and facts about back injuries in nursing. American Journal of Nursing. $2003 ; 103: 32$.

[43] Clemes SA, Haslam CO, Haslam RA. What constitutes effective manual handling training? A systematic review. Occup Med (Lond). 2010; 60: 101-107. http://dx.doi.org/10.1093/occmed/kqp127

[44] Dawson AP, McLennan SN, Schiller SD, Jull GA, Hodges PW, Stewart S. Interventions to prevent back pain and back injury in nurses: a systematic review. Occupational and Environmental Medicine. 2007; 64: 642-650. http://dx.doi.org/10.1136/oem.2006.030643

[45] Denis D, St-Vincent M, Imbeau D, Jette C, Nastasia I. Intervention practices in musculoskeletal disorder prevention: A critical literature review. Applied Ergonomics. 2008; 39: 1-14. http://dx.doi.org/10.1016/j.apergo.2007.02.002

[46] Hignett S. Intervention strategies to reduce musculoskeletal injuries associated with handling patients: A systematic review. Occupational and Environmental Medicine. 2003; 60: e6.

[47] Koppelaar E, Knibbe JJ, Miedema HS, Burdorf A. Determinants of implementation of primary preventive interventions on patient handling in healthcare: a systematic review. Occupational and Environmental Medicine. 2009; 66: 353-360. http://dx.doi.org/10.1136/oem.2008.042481

[48] Martimo K-P, Verbeek J, Karppinen J, Furlan A, Takala E-S, Kuijer P, et al. Effect of training and lifting equipment for preventing back pain in lifting and handling: Systematic review. Bmj. 2008; 336: 429-431. http://dx.doi.org/10.1136/bmj.39463.418380.BE

[49] Verbeek J, Martimo K-P, Karppinen J, Kuijer P, Viikari-Juntura E, Takala E-S. Manual material handling advice and assistive devices for preventing and treating back pain in workers. Cochrane Database of Systematic Reviews. 2011; 6. http://dx.doi.org/10.1002/14651858. CD005958.PUB3

[50] Iakovou G. Implementation of an evidence-based safe patient handling and movement mobility curriculum in an associate degree nursing program. Teaching and Learning in Nursing. 2008; 3: 48-52.

[51] Macdonald W. Workload, stress and psychosocial factors as hazards for musculoskeletal disorders. Journal of Occupational Health and Safety - Aust NZ. 2004; 20: 37-47.

[52] Hignett S, Fray M. Manual handling in healthcare. In Proceedings of the 1st Conference of the Federation of the European Ergonomics Societies [FEES]: 10-12 October; Bruges, Belgium. Edited by Institute of Ergonomics and Human Factors, on behalf of FEES/ECE:2010

[53] Hignett S, Lu J. Space to care and treat safely in acute hospitals: recommendations from 1866 to 2008. Applied Ergonomics. 2010; 41: 666-673.

[54] Rycroft-Malone J. The politics of the evidence-based practice movements. Journal of Research in Nursing. 2006; 11: 95-108. http://dx.doi.org/10.1177/1744987106059793

[55] Patton M. Evaluation in the 'new' knowledge age. Evaluation Journal of Australasia. 2001; 1: 30.

[56] Kay K, Glass, N. Debunking the manual handling myth: an investigation of manual handling knowledge and practices in the Australian private health sector. International Journal of Nursing Practice. 2011; 17: 231-237. http://dx.doi.org/10.1111/j.1440-172X.2011.01930.x

[57] Kneafsey R, Haigh C. Learning safe patient handling skills: student nurse experiences of university and practice based education. Nurse Education Today. 2007; 27: 832-839.

[58] Mitchell T, O'Sullivan PB, Burnett AF, Straker L, Rudd C. Low back pain characteristics from undergraduate student to working nurse in Australia: a cross-sectional survey. International Journal of Nursing Studies. 2008; 45: 1636-1644.

[59] Kent B, McCormack B, ed. Clinical context for evidence-based nursing practice. UK: Wiley Blackwell, 2010.

[60] Charney WD, Simmons B, Lary MA, Metz S. Zero lift programs in small rural hospitals in Washington State: reducing back injuries among health care workers. AAOHN Journal. 2006; 54: 355-358.

[61] Menzel NN. Underreporting of musculoskeletal disorders among health care workers: research needs. AAOHN Journal. 2008; 56: 487-494.

[62] Safe Work Australia. Work-related injuries in Australia, 2005-06: factors affecting applications for workers' compensation. Canberra: Safe Work Australia, 2009.

[63] Rapley T. Doing conversation, discourse and document analysis. London: SAGE Publications, 2007.

[64] Folkmann L, Rankin J. Nurses' medication work: what do nurses know? Journal of Clinical Nursing. 2010; 19 : 3218-3226. http://dx.doi.org/10.1111/j.1365-2702.2010.03249.x

[65] Taylor B, Kermode S, Roberts K. Research in nursing and healthcare: Evidence for practice. Melbourne: Thomson, 2007.

[66] Walter R, Glass N, Davis K. Epistemology at work: the ontological relationship between feminist methods, intersubjectivity and nursing research - a research exemplar. Contemporary Nurse. 2001; 10: 265-272.

[67] Georges J. Evidence of the unspeakable: biopower, compassion, and nursing. Advances in Nursing Science April/June. 2011; 34: 130-135.

[68] Roberts SJ, DeMarco R, Griffin M. The effect of oppressed group behaviours on the culture of the nursing workplace: a review of the evidence and interventions for change. Journal of Nursing Management. 2009; 17: 288-293.

[69] Rose J, Glass N. The importance of emancipatory research to contemporary nursing practice. Contemporary Nurse. $2008 ; 29: 8-22$. 